\title{
Tuberculosis sanatorium regimen in the 1940s: a patient's personal diary
}

\author{
Raymond Hurt FRCS DHMSA
}

J R Soc Med 2004;97:350-353

This article reproduces extracts from a diary that was begun in 1944 and was written spontaneously as events and treatment permitted. The first part describes the thoughts and emotions of a professional woman of 32 who was suddenly separated from her husband, Bill, and fifteen-month-old baby, Mark. The second part narrates the strict routine of sanatorium treatment for pulmonary tuberculosis in the 1940s before the introduction of streptomycin therapy. The diary covers a period before the introduction of the National Health Service and gives an insight into the financial implications of medical practice at that time. References to family and current events have been excluded.

$$
* * *
$$

\section{4}

1 April My idea is partly to keep a record of the happenings and emotions of this period in one's life, and partly to let off steam when I am fed up, rather than in letters or by word of mouth. So for both reasons I shall set down what I really think. If one thing in life is more certain than another, it is that after the first genuine rush of emotion, other people are not interested in one's troubles. So this diary shall be my confidant.

It was on Friday 3 March that I suddenly coughed up mouthfuls of blood. I phoned the doctor, who said that he would call later in the evening. I gave Mark his tea, put him to bed, did some ironing, had my supper when Dr Henderson [general practitioner] arrived. Said I ought to go to bed and stay there-explained that I had no help, so he said 'do as little as possible in the morning and go when Bill comes home at $1.30 \mathrm{pm}$ ', and he would come again in the afternoon. Thought I had better have a cook up for Bill. I little knew it would be the last cooking I should do for a year or so!

X-ray arranged for Monday-I was still fairly convinced it was nothing and a few days would see me through it. Result on Thursday - tuberculosis in right lung. Sanatorium for 6-9 months, and in a year or so I should be completely cured. I had by then nerved myself for this possibility and wasn't too much upset but poor old Bill was completely unnerved-mainly because of my being separated from

The White House, 8 Loom Lane, Radlett, Herts WD7 8AD, UK
Mark — no thought for his own upheaval of having his home split up and all the anxiety, trouble and expense.

On Monday the 10th Dr Henderson brought Dr Wallace. We understood he was a specialist and were getting out our cheque book and expecting the worst - but it turned out he was the Tuberculosis Medical Officer for Surrey under the Government scheme and free! The main thing was that for 2-3 months I needed nothing but complete rest. Then a further X-ray, and if I was coming on satisfactorily, continue similarly. If not, sanatorium and collapse the lung etc. Oh God, only when I realized I could still see Bill and Mark did I let myself think what it would have been like to have been away from them for so long. Mark will walk, talk and change completely during the coming year-nearly half his small life. And as for Bill-I know that millions of wives have their husbands away, but still_-husband and baby at once!

Mark already ignores me. I think it is because I am in bed and I am a 'stationary' object, because once or twice at home when he saw me up and on the way to the toilet he evinced great interest at once. I am absolutely determined to check myself in any tendency to be sad when I see him forgetting and ignoring me, because what matters is that he shall be happy where he is. It is a mercy that he is at an age when 'now' is everything. It takes only a day or so to adjust himself completely to new people. I know Bill is right when he says that when I do come back to him he will, within a week, be as though I had never been away.

I shall always give him a sweet and keep one or two special toys here-cupboard love, I know. We are letting the house furnished to help with the expenses. [She, Mark and Bill moved to her mother's house.]

2 April The great thing is to work out a few simple rules of life and stick to them. First, the purely physical ones made by the doctors.

The rules are:

1 Absolute and utter rest of mind and body - no bath, no movement except to toilet once a day, no sitting up except propped by pillows and semi-reclining, no deep breath. Lead the life of a log, in fact. Don't try, therefore, to sew, knit, or write, except as occasional relief from reading and sleeping

2 Eat nourishing food and have plenty of fresh air. 
Then my own rules to myself:

1 Never give way to self pity. List the disadvantages and then, having conquered them, forget them - they are losing Mark, not being able to have another baby which we had planned, expense and finally boredom

2 Always appear cheerful. Partly for self-discipline and partly because people will soon get sick of me if I don't

3 Interest myself as much as possible in outside thingsboth world-wide, through the newspapers, books and also personal (our friends' affairs, troubles and joys, and those of anyone else I hear of). In other words, cultivate an extrospective and not an introspective outlook

4 Try and improve my mind by reading and thinking, and use this period as one of rest, refreshment and study, in preparation for trying to make some constructive contribution to the good of the world

5 Do not talk about myself and my illness

6 Do not organize other people (very easy habit to fall into when you are lying in bed doing nothing, and most irritating for people who are up and busy and think 'yes, it's all very well for her...')

7 Reconcile myself to avoid movement myself

8 Later on, try writing articles, partly for amusement and partly to earn a little money. In the meantime make notes for same when anything occurs to me

9 'Blessed is he that expecteth nothing', i.e. don't expect Bill and other people to be always coming to see me; cultivate the habit of being pleased when they come and not aggrieved when they don't, so that it never becomes a duty to them.

13 April The second sputum test is still negative. Dr Wallace hopes that the X-ray in a month will show an improvement - and if it does I shall begin to get up a little - and if all goes well, he thinks I might be home in 6 months or so. Asked nurse this morning whether tuberculosis is hereditary. She says definitely not. Once I am cured I can have more babies though I shall not be allowed to feed them. The reason is that once you have tuberculosis it can, though healed, break out again when you are overstrained.

27 April Dr Wallace came yesterday and I can get up! For one hour every day, just to sit in a chair — and can also have a bath.

11 May Doctor came yesterday and I can hardly believe it's true, even though he led us to expect it. I am much better and he is confident I will so continue. I can get up and go downstairs, then begin short walks, a few yards more each day. In about a couple of months I should be leading a fairly normal, though careful, life and by October go back to our own home! The only stipulations then are that I don't get tired. 'Whatever happens - stop in the middle of a job', he says, 'rather than get tired'. And no more babies for at least a year. So there we are - we have so much to be thankful for - that it was discovered so soon and that I was in a position, unlike so many poor devils, to rest as I was told to do.

24 May I am now getting up for tea and dinner, and this afternoon I am going to dress. I can walk without feeling shaky now but my heart beats like mad and I get very breathless if I use my arms or bend down.

31 May Last Wednesday I apparently did too much and felt very exhausted and also had a queer little pain in my chest which did not go and a rise in temperature, so had the doctor in and he said he thought it was nothing to do with the lungs, but stay in bed till temperature settled down.

11 June Now sitting in the little sheltered cove of the garden. I am now having in excess the leisure to sit out of doors which I have always missed.

19 June The doctor came on Wednesday and won't be coming again! (all being well). He gave me more or less the same instructions again - proceed very gradually with the exercise, doing one new thing a week, but do proceed, don't remain static. Gentle walking is good but no prolonged effort and nothing to make me puff. As much fresh air as possible. Betty [a friend] tells me of a girl friend of hers, TB not diagnosed for 18 months, then too late and now just waiting to die. What luck I did have.

9 October X-ray practically clear so we can go home when we like.

25 November I do cooking, shopping and most of the housework, but no polishing, washing or ironing.

\section{5}

30 January Haemorrhage when coughed whilst sitting quietly in lounge after dinner. Went to bed but continued bleeding three to four times a day, some slight, some nasty, till a very nasty one on Friday evening. Didn't move or speak above a whisper all Saturday and managed not to have any more, though I could feel it all there.

12 February X-ray showed a cavity. Doctor advises specialist from town, attached to Brompton Hospital- Dr FH Young.

17 February Dr Young advised collapsing right lung — says left fortunately unaffected. Suggests private ward (i.e. 2, 3 or 4 beds) at Brompton and then home, or Frimley (a country branch of Brompton) straight away and stay there until fit to take up semi-normal life again. Brompton 5 guineas [modern equivalent $=£ 130$ ] a week inclusive or private room at Frimley 4 guineas a week inclusive. The latter rough as regards comfort but excellent as regards 
treatment. The whole job, to take me back to the sort of life I was leading in January this year, should be about a year, if all goes to plan. He told Bill that it should be curable - or rather healed - it is never cured, of course. Mentioned that we might get a contribution towards the cost from the County Fund. Must follow that up. Fee for Dr Young 20 guineas [£525] (including return travel London to Woking 60 miles). As there is a waiting list of 3 4 months for all sanatoriums, however cheap or dear, we left it to Dr Young to find out where I could go sooner.

21 February Well, it is a bitter disappointment-and, of course finish to any more family - even adopting one would have to wait a long time, till I am home again and we can, money permitting, have more help. I feel bitter and very miserable but have reached a few pretty definite conclusions. First, I think that when one has got this disease it is wise to undergo the sanatorium routine and discipline, and after a period of that, plus constant association with doctors and nurses who specialize in $\mathrm{TB}$, anyone with some intelligence must surely learn how to treat oneself - and it is a bit of an insurance policy for the future, because I feel now that one can never be sure that it will not recur again.

I feel hopeful about Mark remembering me again when I come back, because though last time he got quite out of the way of thinking about my being anything but an inanimate object, and used to distress me terribly by crying for someone else if I got him out of his pram or bathed him, yet within a week or so of our being back he was always trying to come to me.

25 February To be admitted to Frimley within about 3-4 weeks.

1 March Printed form from sanatorium to say I should take with me some waterproof boots, a mac and a suit of working clothes.

6 March Well, I'm here. Huge place in nice grounds amongst pine trees. My room not small, very pleasant-big french windows divided into halves like stable doors, looking onto part buildings (not too near) and birds to be seen and many heard. The most striking thing is the friendliness of everyone - all the nurses seem to be young, pretty and perfectly charming. It is a really nice atmosphere.

The meals are priceless. First someone flies in with a plate with two very stale slices of bread and a pat of butter, and a large thick mug in which stands a knife and fork. Some time later (this is supper but they all follow the same pattern-mutatis mutandis), a plate of cold meat and potatoes arrives followed by a nurse with a large enamel mug each of tea and cocoa. No teaspoon; you have the choice of stirring with the meaty end of your fork or the meat. And, of course, no separate knife for the bread and butter. Everything is marked with your number but the nicest touch of all is that every knife, fork and spoon is engraved with the word 'Stolen'.

Almost as soon as I arrived and got into bed I went to see the doctor - a young, boisterous and friendly manwho took down my life history, literally from the day I was born, in the greatest detail. A nurse said she had asked a woman doctor (Dr Morris - a patient) in the next room to mine to call for me at $8 \mathrm{pm}$ as it was weighing night. She did so, a pretty and very talkative young thing, pleasant and laughed at the boarding school-cum-army atmosphere of the place but said you soon get used to it. We went along to the room where dozens of girls and women-mostly very young looking — were waiting in a queue in dressing gowns (again shades of school).

I am on 'basins'. Everyone is 'on' something. 'Absolute' is entirely in bed, 'basins' is getting up to wash in own room (mine is a basin and taps) and go along to the toilet, 'OTW' is out to wash, through 1 hour up, 2 hours up to 4, and then 'exercise', 1 round, 2 rounds up to 6 , and then 'grades', which is work, graded upwards. All very interesting. Spoke to one other person in the weighing room-seemed pleasant and serious-only allowed to whisper or, as she puts it, 'I'm on whispers'. 9.30 pm lights out. Thank goodness windows wide open.

Didn't sleep, of course, till early this morning but did get a bit between $5.30 \mathrm{am}$ (when they take your temperature) and $7 \mathrm{am}$ when night sister burst in on her round and woke me out of a lovely slumber to ask if I'd slept! 7.30 am they make your bed and you wash. $8.30 \mathrm{am}$ breakfast-porridge, bacon and fried bread, butter and marmalade, but only one cup of tea. Then a constant stream of nurses, orderly with a clean hankie (provided by the house), patient with newspapers, maid to sweep the floor, nurse to dust, sister on her ward round etc. All nice and Sister, elderly and very straight-Jane-looking but turns out to be gentle and kind, who tells me not to bother about the book of rules - they will tell me what to do or if I am doing wrong - and that although visiting days are Thursday and Sunday 2-6 pm, I can, whilst I am in bed, have anyone any day $3.30-5.15 \mathrm{pm}$.

The said book of rules begins by saying that 'It is expected that any patient that cannot adapt herself to these necessary restrictions will inform the Medical Superintendent and make immediate arrangements for transfer to an institution more suited to her tastes', and that 'she will not endeavour to make herself more comfortable by lack of discipline which can hinder the staff and make matters more difficult for fellow patients'. It goes on to say that two rules are absolute-1. 'No alcoholic liquor may be brought onto the premises or consumed on or off the premises by any patient', and 2 'No patient may have any 
communication with patients of the opposite sex', and Dr Morris tells me that means if one passes a man in the grounds one may not say 'good morning'!

8 March Auntie brought a large fruit cake this afternoonuseful to give around to Dr Morris and also the nurses, who always seem pleased to see anything to eat. I now feel as though I've been here for years.

17 March Haven't written this for some days because five days ago I had my AP [artificial pneumothorax]. ${ }^{1}$ Quite interesting, though nothing much to see. I had the AP at $10 \mathrm{am}$ - local anaesthetic and didn't feel anything. I slept till $1 \mathrm{pm}$ and woke feeling awful. Chest very painful and couldn't get into a comfortable position in bed.

19 March On absolute rest all day, i.e. one pillow, lie flat and don't read. The next day moderate rest i.e. two pillows, still lie flat and don't read. Rather awkward eating and drinking flat on your back! Wednesday, by which time I felt well again, on 'BNGU', meaning bedpans and not get up but allowed to sit up and write. The idea is to rest your other lung and heart whilst they readjust, apparently.

Had a refill on Tuesday and again on Thursday-local anaesthetic each time and no after-effects - simply don't notice it. Yesterday had 'screening', i.e. an X-ray but they don't take a plate. They just look at a screen and make notes at the time. I heard Dr Goddard say 'good general collapse', so I hope for the best. They put the air in only gradually. Screening is an odd business - I was taken down in a chair and you go into a completely dark room and stand in the X-ray thing, all in the dark — most eerie - but you are in and out in a few seconds.

24 March I have been put on 'basins' and have had another refill and screening. Heard Dr Myers say 'good general collapse' so apparently so far so good.

27 March A rumpus yesterday because Dr Morris keeps coming into my room; one of the nurses has got into trouble over it, so of course we must stop - but she is up for two hours now and it seems absurd that she can't drink her tea in here.

9 April Well, I've got chicken pox! We had quite decided that Bill was not to come whilst the chicken pox lasts but he popped in; he touched nothing and stood with his head out of the window so there probably wasn't much risk.

30 April Well, at least I got out of quarantine last Wednesday, after $3 \frac{1}{2}$ weeks - lovely to be out and on three hours, with lunch in the day room. Four hours on Saturday and five today, so up for supper for the first time. Mrs Pratt visited me today — she has had a thoracoplasty after having tuberculosis and varying treatments on and off for twelve years [thoracoplasty is an operation done in three stages in which long lengths of up to eight ribs are removed to collapse the chest wall and rest the underlying lung]. ${ }^{2}$
7 June Weekend at home.

2 July Grades - told adhesions to be cut.

21 September Adhesion section-Mr Price Thomas.

4 November One month rest in bed at home - up four hours a day.

2 December No refill. Proceeded on Frimley course, increasing walking to six rounds and then one week gardening.

\section{6}

10 January X-ray. Dr Myers says 'left side needs watching'.

5 February Saw Dr Young at 31 Weymouth Street. He advises bilateral AP and will arrange for me to go to Frimley. Says left side is not very bad. I am to have no refill till 21 February so as to let right side up ready for left collapse. To stay in bed in meantime, on 'OTW'.

21 February Refill. To come fortnightly henceforward. Dr Myers told me that due to Frimley closing beds there is no chance of me getting in there for many months. Suggest ringing Dr Young? go to Brompton or somewhere else.

22 February Rang Dr Young. Brompton waiting list 3-4 months. Nursing home 15 guineas a week plus medical expenses [in modern money £385]. Rang Dr Young's secretary to see if he approves of Holy Cross at Haslemere -4 guineas a week.

5 March Went to Haslemere and left AP induced.

4 June At own request went home. Dr Myers told me to get up gradually. From then on weekly refills on left and fortnightly on right until nearly end of 1947 when fortnightly on both sides.

June onwards To Frimley for refills for two years.

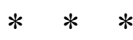

In 1949 she was told she could become pregnant and her second baby was born on 9 February 1950. Subsequently she led a fully active life and died aged 86 years from an unrelated cause.

Acknowledgment: I am indebted to Mr John Anderson, son of my distant cousin, for giving me access to her personal diary. Her self-discipline and stoicism was quite remarkable, as also was her determination to do everything she was asked to do without question.

\section{REFERENCES}

1 Hurt R. History of Cardiothoracic Surgery. Carnforth: Parthenon, 1996:205

2 Hurt R. History of Cardiothoracic Surgery. Carnforth: Parthenon, 1996:213 